$$
\text { conf. } 790125-.17
$$

\title{
A REVIEW OF LIFETIME ANALYSES FOR TOKAMAKS
}

\section{by}

S, D. Harkness and B. Cramer

Prepared for

First Topical Meeting on

Fusion Reactor Materials

Miami, Florida

January $2 y-31,1979$ 


\section{A REVIEW OF LIFETIME ANALYSES FOR TOKAMAKs*}

S. D. BARKNESS and B. CRAMER ${ }^{\dagger}$

Argonne National Laboratory, Argonne, I111no1s 60439, USA

System studies have vividly shown that economic fuston power can only be achieved from the use of long lived components. Lifetime goals of $90 \mathrm{MH}-y \mathrm{r} / \mathrm{m}^{2}$ for a tokamak based power plant should be established. The stresses generated in a first wall module are a complex function of its geometry, the chosen structural material and the tokamak burn cycle characteristics. A formalism based on the foundation ASME Code Case 1592 has been established. wethods of $i$ corporating sotie of the changes expected from irradiation are discussed. The cyclic stress.pattern impostd by tokamak operation is expected to cause fatigue related properties to govern the life of the structure. Stress assisted bubble growth is suggested as the possible critical mechanism in establishing the stress-to-rupture life of a fusion first wall component.

\section{INTRODUCTION}

To be a viable part of the vation's energy supply system, fuston based ruactors w111 have to prove themselves both as reliable and an economical alternative energy scurces. A very Important factor in whether ir not fusion reactors ever become Important produce:s of electrifity is the expected Iffetime of key reactor components. This paper is in attempt to review the status and results of the lifetime analysis work performed, to date, for tokamaks.

System study $[1,2]$ results are useful for putting Into perspective the importance of achieving long lived desiyns. Figure 1(a) and 1(b) compare the operating costs as a function of neut on wall loading essuming the existence of a $10 \mathrm{MW}-y r / \mathrm{m}^{2}$ design in $1(\mathrm{a})$ and a $30 \mathrm{MW}-$ $\mathrm{yr} / \mathrm{m}^{2}$ design in $1(\mathrm{~b})$. The achlevemenc of relatively high 2-3 $\mathrm{mH} / \mathrm{m}^{2}$ will loadings has been

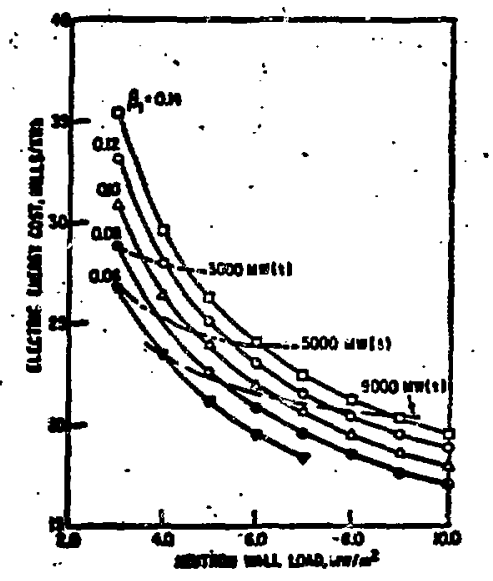

P18, $1(a)$

$\star$ Tate work was supported by the D.S. Departmer: of Bnergy

* McDonneli Douglas Astronautics Company, st. Louts.



F18. 1(b)

Increasingly widely recognized [3] as a key means of reducing the size and, in turn, the capital cost of a tokamak-based reactor.

The maln reason for the economic Incentive shown in Fig. I for longer lived designs is the long time required Eor rebullding of a tokamak system. To date, no one has been able to identify a means of in-situ repair so that the tedious and laborlous disassembly of large, welded, radloactive components must be envistoned. A length of 80 days to rebulld a rokamak sysrem was used in analysis that led to F1g. 1. Viewed in another way, the lost revenue from one days operation of a $1000 \mathrm{MHe}$ plant where electricity is sold at five cents a $\mathrm{KW}$ hr is 1.2 million dollars.

The effect of planned maintenance, alone, is sufficlent to fustify (Indeed dictate) the development of a long lived design. However, there is additional incentive for such a development from a consideration of the relationohip between expected component ilfetime and the occurrence of unscheduled shutdowns. Failure Is by its very nature a statistical phenomenon. It is imposstble to say precisely when a component w11l fail, as one lo restricted to a 
statement of the sort that there is a $95 \%$. probablitty that faflure will not occur before a certain point in time. Putting this in simplest terms, if one assumes a functional form such as $e^{-t} / \tau_{L}$ where $t_{L}$ is the expected component lifetime and $t$ is the actual life, ther a certain probability of fallure can be ascribed to a particular component. The actual number of fallures to be expected in the system will be the product of the number of components times this probability. Many fusion reactor system deaigns involve hundreds or even thousands of firat wall. modules. For a short lived design the number of projected component fallures would be much higher than for a long lived component over the whole lifetime of the reactor plant, $t_{r}$ 1.e. the number of expected fallures is a $t_{r} / t_{p} \times e^{-t_{p} / t_{l}}$ where $x$ is the number of moduleg in th: design and $t_{p}$ is the ?ength of period between scheduled maintenance operations. Clearly higher values of $t_{p}$ results in a reduction in the number of expected failures during the life of the plant.

$\because$ Thus system studies on the economics of fusion power indicate the incentive to achleve an expected component lifetime equal to that of the. reactor plant or 30 years. To be useful, this Iffe must be achleved for wall loadings of frow 2-3 $\mathrm{MW} / \mathrm{m}^{2}$, thereby creating an overall goal of $90 \mathrm{MW}-\mathrm{yr} / \mathrm{m}^{2}$.

\section{LIFETIME ESTIMATES}

Lifetime estimates are dependent on criteria developed in three categorles. The first of thase Includes those things that actually lead to fallure of the component, elther through leakage of the coolant or by a complete fallure of an element. creep-fatigue and flaw propagation would fall into this most obvious class.

The second class involves limits on dimensional change that would cause some planned operation to become impossible. Swelling and creep are the main considerations in this category. Setting limits for allowable dimensional change is very design dependent and can only be done after all planned maintenance operations are well established. A more stringent restriction ou the amount of allowable swelling may well result from an analysis of the effect of the stresses induced by the swelling gradients on class one properties.

The third class comprises limits on deformation that experience has shown are Important. to prevent the structure from falling in an unspecifled mode. Thermal ratcheting limits 18 an Important example in this category.

To begin to analyze the performance of a reactor module in terms of these three categorles of properties, one must first characterize the environment in terms of the expected ocress and thermal history.

\section{3. .. THERMAL-HYDRAULIC CONSIDERATIONS}

Any detailed estimate of the 11fetime of a tokamak ftrst wall module must be based on a complete thermal-hydraulic analysis, such as is Included in references [4] and [5]. For the purposes of this review, certain fundamertal imitations on performance result directly from the selection of a structural material and a wall thickness. The maximum temperature of the first wall molule can be no lower than the coolant temperature plus the quantity $\mathrm{w}_{\mathrm{g}} \mathrm{t} / \mathrm{k}$ where $W_{s}$ is the surface heat $f_{1 u x} t$ is the wall thiskness, and $k$ is the thermal conductivity of the wall. The actual wall temperature w111. of course, be wigher since the heat transfer between the wall and the coolant stream will never be perfect. If one assumes as a basis of comparison a coolant stream cemperature of $225^{\circ} \mathrm{C}$, the relationship between temperature and wall thickness for three candidate materlals are as presented in Table 1. While each of these three candidates, Type 316 stainless steel, a stabilized $9 \mathrm{Cr}$ ferritic stainlese, and a titanium alloy (TI-6AI-4V) have an upper temperature limit of about $500^{\circ} \mathrm{C}$ in a fusion reactor environment, it can be seen thet widely different wall loading limits nre strictly from the radial temperature gradient. Titanium alloys suffer from the fact that they are restricted to oervice wall loadings below $\sim 4 \mathrm{MW} / \mathrm{m}^{2}$.

The temperature gradients developed within the wall result in secondary stresses of both . thermal and radiation swelling origin. The magnitude of these stresges wili be considered in the next section.

\section{SOURCES OF STRESS}

The results of an analyols for one tokamak wall design is presented in Fig. 2 to illustrate the changing stress pattern that must be expected with time. The primary stresses existent in a tokamak system are a result of the coolant pressure and magnetic forces if a magnetic structural material such as ferritic stainless steel

Table 1.

\begin{tabular}{|c|c|c|c|}
\hline $\begin{array}{l}\text { First WRLL } \\
\text { ALOT }\end{array}$ & $\begin{array}{l}T \text { ACRoss } \\
1 \mathrm{CM} \text { WALL, AT } \\
1 \mathrm{MH} / \mathrm{H}^{2},{ }^{\circ} \mathrm{C}\end{array}$ & \multicolumn{2}{|c|}{  } \\
\hline . & . & $530^{\circ} \mathrm{C}$ & $400^{\circ} \mathrm{C}$ \\
\hline 316 & 108 & 8.5 & 5.4 \\
\hline$T 1-6 T_{l}-4$ & 198. & 4.8 & 3.0 \\
\hline Fernatic, 9-Cr & 86 & 10.6 & 6.7 \\
\hline
\end{tabular}

- Assures coolant inlet temeratune of $25^{\circ} \mathrm{C}$. 


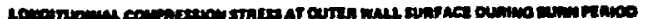

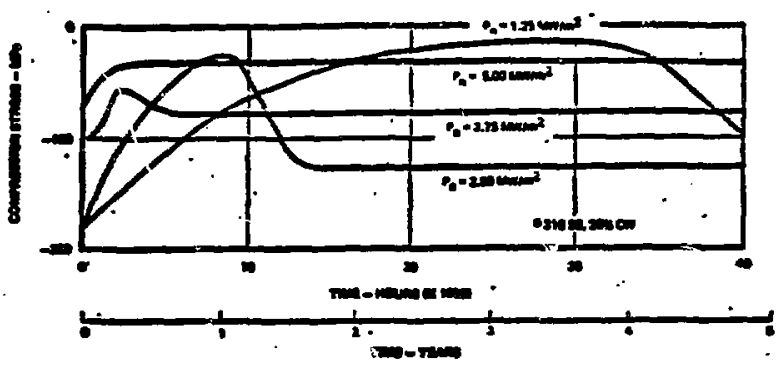

Fig. 2.

18 ured. The coolant pressures range from atmospicric for a faliing bed concept to as high as $1 j .7 \mathrm{MPa}$ for some water cooled designs: Representation pressures-are shown in Table 2 for each of 5 coolant choices as developed by recent blanket studies [6]. The magnetic force that results from the use of a ferromagnetic structural material can also result in signif1cant stresses. Recent calculations [7] for a 9-Cr stablized ferritic stainless steel structure Indicates stresses of $\sim 1$ atin will be 1mpissed if this material ts used.

A possible source of cyclic primary stresses are pressure fluctuations due to turbulence in the coolant that could contribute to fatigue failure in first wall structures. In addition, plasma disruptions may cause electrical currents to flow in first wall structures resulting in internal forces. These must be combined with other primary laads in determining structural thicknesses. These forces and their resulting dynemic effects on stress have been shown to have a signfficant effect on structural design

Table 2.



and on resulting component life [8]. Because these disruptions may occur frequently (assumed once each 10 cycles in Ref. [8]), they may have to be constdered a normal loading condicton.

In addition to these primary stresses as the onset of operation, the incident electromagnetic and particle fluxes that comprise $\sim 25 \%$ of the total fusion energy cause large compressiv/ thermal stresses to be generated in the first wall surface facing the plasm and a corresponding tensile stress to be generated on the coolant side of the wall. The initial level of these secondary stresses depends on the material selection, the wall loading, and the wall thickness. Representative values for several materlals are shown in Table 3 .

Table 3.

$$
\sigma_{\mathrm{T}}=\text { aE } \Delta T=a_{\mathrm{E}} \frac{\mathrm{H}}{\mathrm{R}} \mathrm{T}
$$



\begin{tabular}{|c|c|c|c|c|}
\hline \multirow{2}{*}{$\begin{array}{l}\text { Structual } \\
\text { Mitental }\end{array}$} & \multirow{2}{*}{$\begin{array}{l}\text { Yielo Stuensth } \\
\text { Ar } 500^{\circ} \mathrm{C} \\
\text { (pai) }\end{array}$} & \multicolumn{3}{|c|}{$\begin{array}{l}\text { Trepmal StRess at } \\
\text { Mell Lovotws }\end{array}$} \\
\hline & & .1 & 3 & 5 \\
\hline $\begin{array}{l}316 \text { staimses } \\
\text { sted. }\end{array}$ & $\begin{array}{c}195 \\
(28,000)\end{array}$ & $\begin{array}{c}72 \\
(10,400)\end{array}$ & 216 & 360 \\
\hline $9 \operatorname{cR}_{\text {FERATTIC }}$ & $\begin{array}{l}310 \\
(45,000)\end{array}$ & $\begin{array}{c}42 \\
(6.100)\end{array}$ & 126 & 210 \\
\hline Trtaniun & $\begin{array}{c}480 \\
(69,600)\end{array}$ & $\begin{array}{c}34 \\
(4,930)\end{array}$ & 1102 & 170 \\
\hline
\end{tabular}

Figure 3, as taken from the work of Muhkerjee, et al [9], illustrates the importance of 1ncluding the anelastic component in the analysis as it results in a recoverable reduction in the imposed stress of about $15 \%$ in the example case of an austenitic stainless steel structure.

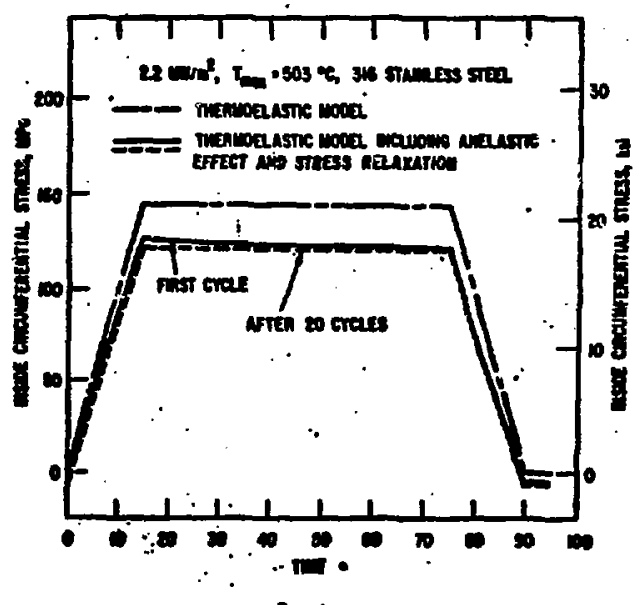

E18. 3. 
Thio streas is then further relaxed by thecmal and radiation enhanced processes that result in permanent deformation of the structure so that eventually the thermally induced secondary stresses are low during the reactor burn and approach the the twoelastic stress less the anelastic recovery during the dwell portion of the burn cycle. Since it is this stress that has been found to govern the fatigue and flow propagation estimates, the importance of the inclusion of the anelastic recovery is evident since crack growth rates are a function of the stress level raised to an exponent ranging from 2 to 4 . Thus the reduction of the estimated stress by 15 percent could result in a factor of 2 reduction in the estimated crack growth rates.

The thermoelastic stress is Impediately reduced by anelastic effects and as a function of tiwe by thermal and radiation enhanced stress relaration.

It should be noted that radiation enhanced. stress relaxation is particularly effective in reducing the level of stress present during the burn due to both Its amplification of the process and its linear dependence on stress. This latter characteristic allows the relaxation process to proceed to much lower stresses than would be reached by the much more highly stress dependent thermal stress relaxation process (P18. 4). Rediátion enhanced stress relaxation eventually causes the plasma side of the wall to be under rather high tensile stress during the dwell period which may have important itiplications for the fatigue properties as surface damage due to blistering and sputtering may aid both crack inftiation and propagation under tensile loading. A very important aspect of the stress relaxation is that it tends to minimize the importance of creep rupture as a life limiting property since the high thermal stresses are only imposed for the relatively short periods between burns and at times when wall temperatures are lower and the neutron flux is absient. This has the effect of translating the tokamak first wall problem into one where fatigue and flaw propagation considerations are of Increased Importance. In addition to the thermally Induced secondary stresses, ancther Important source of secondary stress is due to differential swelling. As shown in $\mathrm{Fig.} \mathrm{2,} \mathrm{for}$ a swelling materlal such as Type 316 stainless Bteel, gradients in vold volume within the meterial result in rather high stresses at long times within the materlal. Also included for purposes of contrast are the expected stresses for a ferritic stainless steel which is assumed not to swell during neutron irradiation.

The gradients in swelling can result in rather complex stress distributions in a structure constructed of a material such as Type 316 stainless steel. An elastic analysis is pregented as FIg. 5 to dramatize this point.

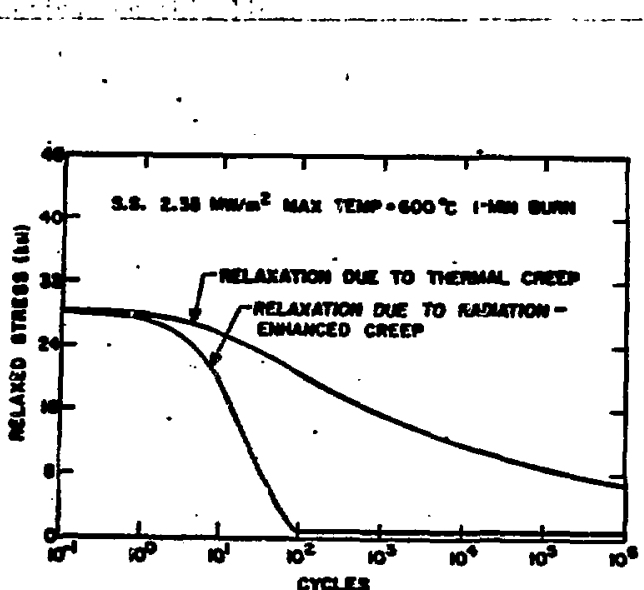

Fi8. 4.

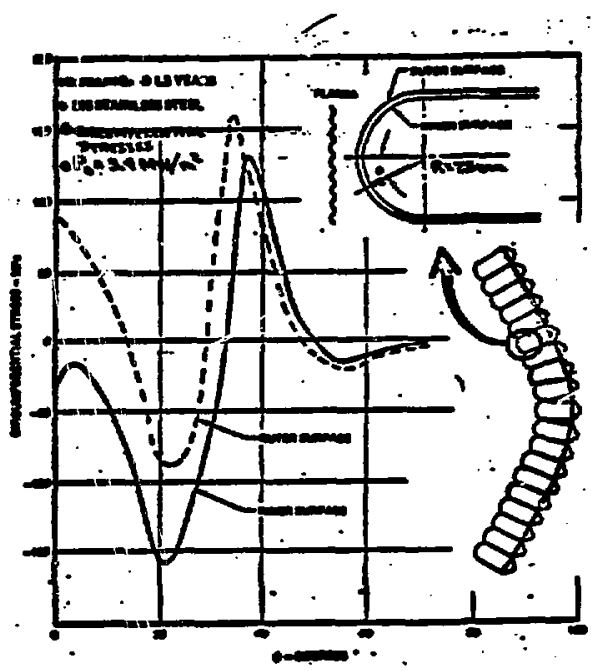

Fig. 5.

Design dependent stress distributions w111 also result from coolant pressures and temperature distributions. Stress historles in the first wall structures, including effects of Irradiation swelling and creep, have been calculated on an inelastic basis in references [9] and [10]. Resulte of the analyses from reference [9] are shown in Fig. 2. These stress historles Indicate the zelaxation of compressive stresses with time due to creep and subsequent increase in compressive stresses due 
to swelling. This relaxation of compressive Btresseg cause residual tensile stresses to result during the "non burn" portion of the cycle. These stress historles were calculated for a uniaxial element in the first wall. They are shown for various levels of neutron wall loading and include a temperature effect (temperature Increnses with increasing wall loading) as well. as a tine dependent 1rradiation effect. The reaults shown in Figs, 2 and 5 provide an Indication of the complexity of first wall stresses due to their time dependent nature, cyclic nature, and the redistribution of gtresses which w11 occur.

In depth analysis of a near term doublet shaped plasma chamber has been reported $[8,11$. 12 and 13]. Because of the rather short operating Iffe ( $\approx 70$ days) of this machine, unirradiated materlal properties were used. However, a detalled analysis of thermal stresses and plasma distuption stresses was included in predicting wall life. A resulting cyclic stress h1story for an Inconel 625 wall is shown in Fig. 6. Reaults included effects of plasticity: to deterofine thermal stress distributions and optimin wall section gtometries as well as a dynamic analysis to determine response of the wall to plesma disruptions. Cyclic stresses due to both effects have a gignificant effect on first wall 11fe.

\section{j. DESIGN APPROACBES TO REDUCE THE LEVEL OF} INDUCED SERESSES

The designer has at his disposal several methods of reducing the level of thermal stresses imposed on the first wall of a tokamak.

One of the most importanc considerations deals with the use of restraint as a means of

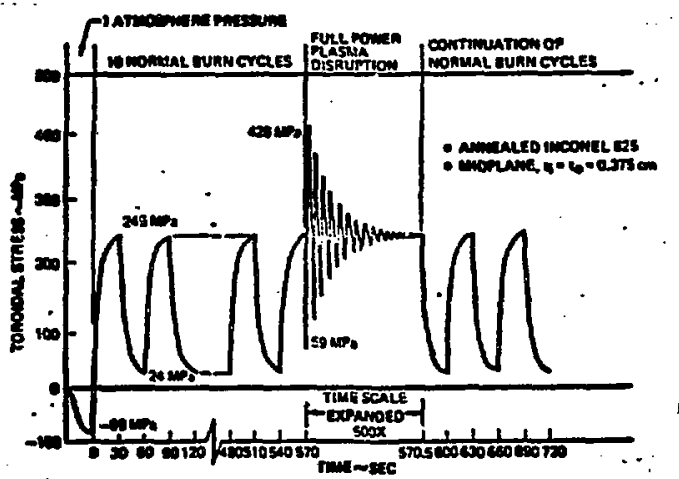

Elg. 6.
IIntting bending stresses. For example, if the hemispherically capped first wall module were not rigidly clauped, then the thermal stresses would be as ghown in Fig. 7 rather than as in Fig. 3. The use of restraint in system design must be approached sarefully when dealing with structural materlals that arc dimensfonally unstable under Irradiation. For example, Wolfer and Watson [14] found if was necessary to avoid all restraint when desigaing a graphite first wall structure due to the stresses that would otherwise be gevarated in this dimensionally unstable materlai.
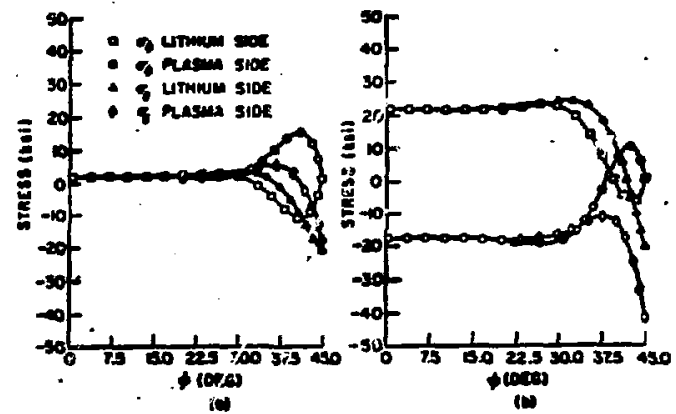

F18. 7.

A number: of ways to minimize the temperature gradlent that is established by the surface heating due to the electromagnetic and particle flux from the plasma have been devised. These generally take two forms, elther reducing the fraction of energy that is deposited on the wall through the use of a divertor to intercept the particle transport, or to spread out the time that energy is radlated to the wall so that some heating continues during the dwell period by means of a liner or limiters.

The effects of a magnetic ilvertor on the temperature and temperature gradients generated In the first wall of a tokamak have been pualyzed by B. Misra and V. Maroni [4]. Their results reflect the fact that over half of the heat flux incident on the first wall surface is due to particle transport so that the use of a divertor effectively allows a factor of two h1gher wall loadings to be imposed on the system for a given allowable thermal stress level.

The application of a liner as a protective first wall device has been analyzed by Kearney [5] et al. A liner is usually included in tolcamak designs to protect the first wall from plasma disruptions that result in a sudden deposition of the plasma's energy onto the first wall. However, this device, which is usually concelved to be fabricated from a coated graphite or silicon carbide, has the additional benefit of flattening the rate of energy deposition onto the first wall during normal 
operation. Figure $B$ compares the expected first wall surface temperature for the case when a Iiner completely covers the inside of the tokank, when refractory limiters comprise 107 of the surface area with that for a bare wall as calculated by Krazinski and Smith [15]. The use of a liner was calculated [5] to increase the crack growth 1 imited lifetime from 2.6 to 89 years.

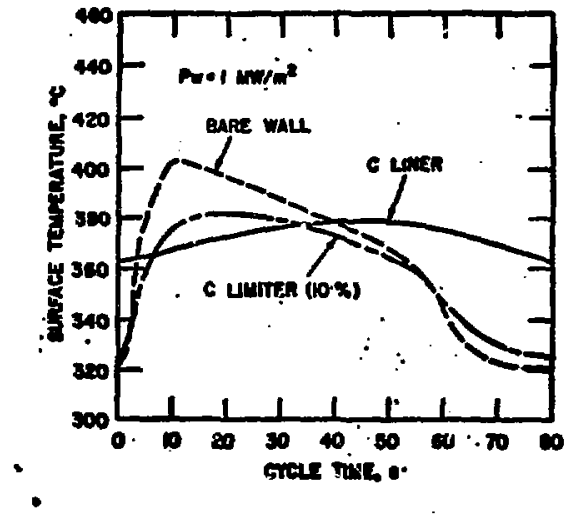

F18. 8.

It should be noted that after stress relaxation has worked to limit the pre;ence of the thermally induced stresses to the downtime between burns, ingenious methods to generate energy in the blanket such as developed for the Numak [3] reactor might serve to aggrevate the problem. The Numak approach uses the solidification of a Pb-Li eutectic during the dwell period to even the temperature swing seen by the turbine. This could serve to also raise the temperature of the coolant side of the first wall, thereby causing an increase in the stress levels already present since stress relaxation during the burn has caused the coolant side to be under compression during the dwell part of the cycle.

\section{IIFETIME CRITERIA}

In developing a method for predicting the lifetime of a fusion reactor first wall module, the logical foundation to build upon is the ASME Code Case 1592 for Class 1 components in Elevated Temperature Service [16]. C. K. Youngdahl and D. L. Smith [17] have developed this approach for a fusion reactor first wall In such a way as to relate the maximum allowable surface he'at flux as a function of the average wall temperature for a number of candidete structurai alloys.

These authors suggest a two step process. In the first step the structure is analyzed for those processes that result in actual fallure of the component such as fatigue, stressto-rupture and excessive primary loading. Based on the use of Code Case properties for the unircadiated materials where they existed, and estimates based on avallable experimental data when they didn't, the authors were able to project good performance in this first step for all materials from annealed Type 316 stainless steel (the worst performer) to vanadium alloys (the best) and still comply with the code Case requirements on tensile, siress-to-rupture and fat igue properties. These authors' results for Type 316 stainless steel are shown in F1g. 9 along with an additional plot of the maximum waj.1 loading possible at a given wall temperature based on the simpified analysis presented in the thermal hydraulics section of this paper. It can be seen that these temperature limits reduce the attractiveness of low temperature systems.

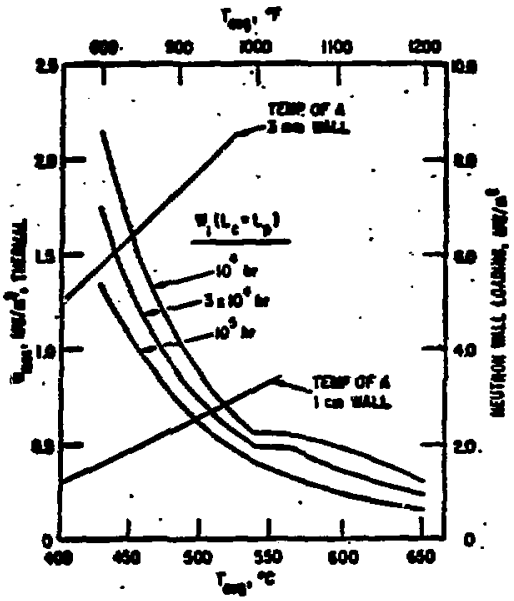

Figure 9 was developed by first establishing the allowable module wall thickness from $\mathrm{S}_{\mathrm{mc}}$, the primary membrane stress limit through the relation $\delta=P R / S_{m, t}$. $S_{m, t}$ is the lesser of the time Independent tensile limits and the time dependent stress-to-rupture related properties. $P$ is the coolant pressure and $R$ is module radius in the above relationsh1p. Th1s value of wall thickness was then used in a fatigue based equation

$$
\varepsilon_{\mathrm{t}}(L)=\frac{\alpha \delta w}{2 k(1-v)}
$$

where $\varepsilon_{\mathrm{t}}(\mathrm{L})$ is the code given allowable strain to achieve the desired iffetime, $W$ is the thermal wall loading (equals $\sim 25 \%$ of the neutron wall loading), a is the thermal expansion coefficlent, $k$ is the thermal conductivity, and $v$ is Polsson's ratio.

In thit second step of the analysis, what were previously termed category three criteria are exanined. These deal with deformation limits on thermal ratcheting and thermal creep whose 
main intent is to minimize the possibility of inftiation of cracks within the material. A useful way of analyzing for the effects of . ratcheting in a thermally cycled system has been developed by Bree [18]. When Youngdahl and Smith extend their analysis to cover ratcheting, the allowable design point drops from - to $\mathrm{MW}-\mathrm{yr} / \mathrm{m}^{2}$ where the fatigue curve plotted in Fig. 10 is taken from F1g:9. Again the results of Including a temperature 11mitation reduces the attractiveness of using a low otructural temperature design.

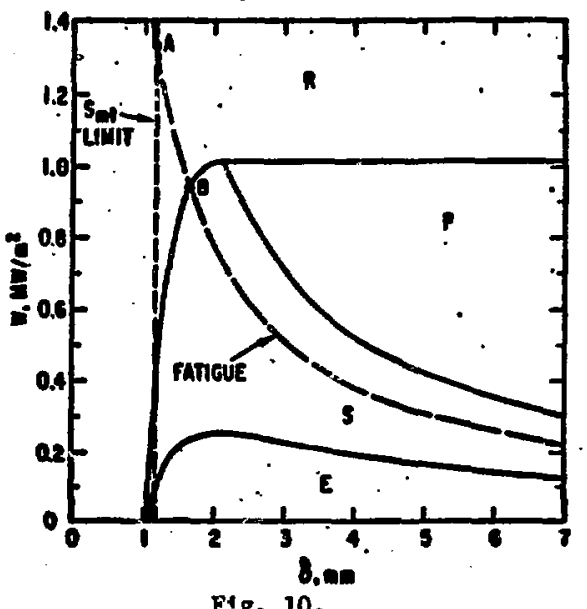

This promising approach to design stops short of including the propagation of existent flaws In the analysis. In one study [19] flaw propagation was found to be the life limiting property. This analysis is dependent on both the essumptions made for Inttial flaw sizes and the applicability of the available data which is for unirradiated material tested.in air.

Within these constraints the crack growth properties necessary to achleve a given 11fetime can be calculated. For Type 316 stainless steel the assumption of the presence of an 0.124 cll flaw depth, a flaw aspect ratio of 0.5 , In a wall of $0.25 \mathrm{~cm}$ thickness resulted in the Information presented as Fig. 11 [19]. For these conditions, a significant improvement in the crack propagation properties are necessary fust to achieve a $10 \mathrm{MW}-y \mathrm{r} / \mathrm{m}^{2}$ life at a wall loading of $2 \mathrm{MW} / \mathrm{m}^{2}$. Based on this calculation, only low stress, low temperature combinations would allow the achlevement of the minimal 10 $M N-y \mathbf{r} / \mathrm{m}^{2}$.

In a study of an Inconel 718 .first: wall module, Kearney, et al. [5] found that wall loadings were limited to less than $\backsim 2.2$ $\mathrm{MN} / \mathrm{m}^{2}$ from their imposition of a $600^{\circ} \mathrm{C}$ maxtmum temperature. For a neutron wall loading of $2 \mathrm{mw} / \mathrm{m}^{2}$, It was found essentlal to detect all flaws larger than $0.75 \mathrm{~mm}$ in deptin in

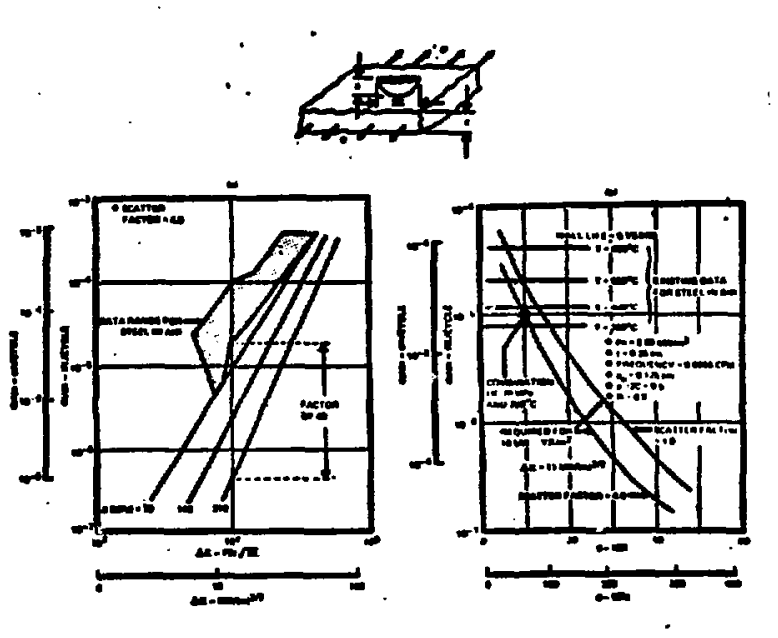

F18. 11.

order to achleve acceptable lifetimes (> $10 \mathrm{~kW}-\mathrm{yr} / \mathrm{m}^{2}$ ) for their $5 \mathrm{ma}$ thick structure.

The question of what is the appropriate Initial flaw size to choose is a difficult one to answer. Fusion devices will, in all probatility, be fleld erected and consist of joining massive components. While it is true that techniques are currently in practice to detect scratches of 0.025 in thin walled tubinz, such schemes may not be applicable to fuston first wall modules. The benefits to be gained in going to better nondestructive testing systems are shown in F18. 12 for a wall of $0.25 \mathrm{~cm}$. If a scratch depth of only 0.025 cm (10\% of the wall thickness) is assumed, a subsrantial improvement is st1ll required in crack propagation properties if economically interesting wall lifetimes are to be achleved.

From this discussion, it is evident that flaw propagation must be included in any lifetime analysis of a fusion device. This should be done after the sriccture has been found acceptable in an an.lysis such as outlined by Youngdahl and Sinth.

With this analysis fravework in.mind, the next step is to extrapolate the available data to conditions presented by the fusion environment.

\section{IEXTRAPOLATION OE DATA}

As descrtbed expertly elsewhere $[20,21]$, the high energy neutron bosmardment characteristic of a fusion device will lead to major afcroseructural changes. These effects are 

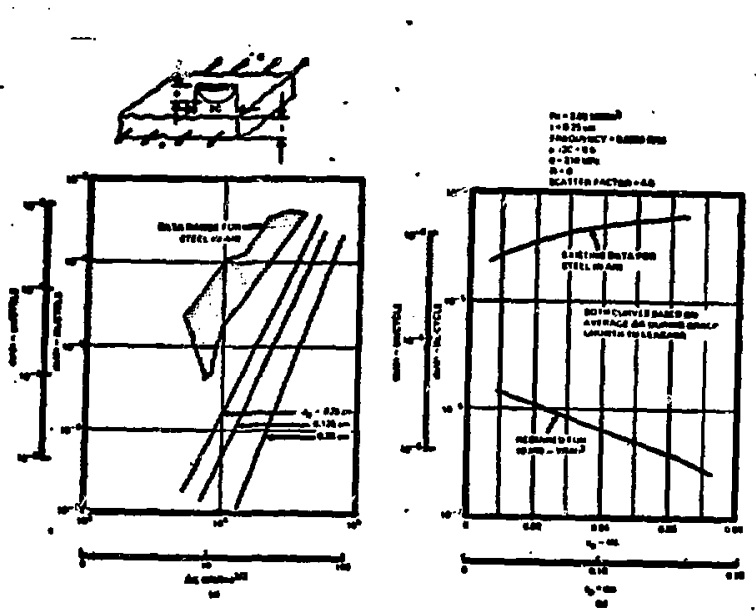

F18. 12.

best documented for the austenitic stainless steels where swelling and ductility loss are perhaps the mosr 1mportant property changes wth fluence. An Importanc [22] paper has recently been presented that deals with the difficult problem of how to incorporate the duetilfty loss into a design approach. In the referenced approach, each of the ASME 1592 Code Case requirements were addressed from the viewpolnt of what addictonal conservatisms should be included when designing with a low (where the defialtion of low changes with the requirement) ductilicy materlal. A major assumption made in this work is that swelling and irradiation creep do not inherently damage the material.

For example, in setting the criterion for the primary membrane stress intensity for unIrradiated materlals, the level must be kept below the $y$ leld stress, $S_{y}$, while for irradlated material whose ductility has dropped below $5 \%$ (or as can be shown to be equivalent, whose yield strength to ultimate strength ratio has exceeded 0.6 ), the allowable level becomes 0.6 of the ultimate strength.

In analyzing the effect of ductility loss on the use of the Bree dlagram to protect against ratcheting, the authors conclude that it must be amended when the uniform elongation is reduced to approximately $1 \%$ for an austenitic atainless steel. At this point the work of Leckie and Porter [23] is used to modify the boundaries in the Bree diagram. These authors have shown that ratcheting strains will be amall when creep is sigaificant if loads are kept less than $n / n+l$ of the elastic-plastic shakedown loads where $\mathrm{n}$ - is the exponent in the creep relation $\dot{E}_{c}=A \sigma^{n}$. If the thermal creep expression is used, then $n^{\prime} s$ of $4-6$ are approprtate and relatively small movements of the IIree diagram bourdaries reault. If the expreasion for radiation enfranced creep is used, then an $n$ value near 1 should be used and wuch larger movements of the Bree boundaries are required. The use of any thermal creep related deformation laws for the prediction of performasace of component during neutron radiation may at: first seem questionable since, for in the temperature range of interest, the time dependent deformation mechanisms for the matrix of the grains of the structural alloy are not those that operate during thermal creep. In other words, creep during irradiation is not a superposition of a radiation enhanced process and a thermal one. However, the importance of Including a lifit on ratcheting has more to do with avolding conditions where cracks are initiated within the material than $\therefore$ : the absolute amount of deformation that occurs. Therefore, what one would really like to know is the amount of grain boundary sliding that occurs for some given amount of total strain. If one assumes that the grain boundary sliding process is little affected by radlation, then the calculation of a nonexistent amount of thermal creep strain may serve as an adequate estimate of the level of the grain boundary sliding (some small fraction of the actual calculated creep strain) that can be incurred without crack initiation.

For this reason, the suggestion by Nelson, et al., to use a total strain limit that is based on a sumation of the ratio of the plastic strain, $\delta \varepsilon P$, to the plastic strain limit, $E P$, and the ratio of the thermal creep strain $\delta c$, to the creep strain limit $\varepsilon_{l}^{c}$ where the limits, $\varepsilon_{L}$ and $\varepsilon^{c}$ are in turn allowetd to vary with fluence and temperature appear's valid. That is

$$
\sum \frac{\delta \varepsilon^{p}}{\varepsilon_{L}^{p}}+\sum \frac{\delta \varepsilon^{c}}{\varepsilon_{L}^{c}}<\beta(\text { where } B<1) .
$$

This approach replaces the fixed 17 limit on strain Imposed by the ASKE Code Case in a manner that is more in keeping with the intent of minimizing the chances of crack formation in a material whose ductility changes as a function of time. In a similar way, the authors recomend a linear summation of the fraction of rupture 11 fe and fatigue $11 \mathrm{fe}$ where each of these is again a function of fluence as well as temperazure and stress.

The authors recrmmend a linear summation of the rupture life fraction and the fatigue 11 fe fraction where these lifetimes are allowed to vary as a function of fluence, temperature and stress. While the linear summation aspect [24] of the approach is open to debate, it does serve to emphasize two properties of special Importance; the fatigue and stress-to-rupture lifetimes expected under tokamak reactor conditions. 
Some experimental information has been obtained on the effect of neutron irradiaction in the vold forming temperature range on fatigue 11fetimes. Wichel [25] has suggested an adaptation of the Univereel Slopes Equation to effectively use the increases in yield strength and reduction in area parameters to adjust for the effects of radiation on the fatigue properties. This epprosch results in a prediction of an improves; ment in properties under high cycle conditions with a reduction at low cycles to fallure. The Universal Slopes Approach has the Inherent problew of choosing the proper ductility parameter to use. For example, if the reduction in area of an irradiated sample is measured at. Low magnifications, very low values are found while a h1gher magnificiation examination of the same aaple will reveal relatively high local reductions due to its tendency to deform a dislocation channeling. It is not evident which of the values of reduction in area is approprlate to use.

Furthermore, this difficulty relates to the larger losue that it may be unreasonable to expect an empirically derived relationship to be valid when the basic deformation mechanisms change. As discussed lucidly by Grossbeck, [20] the clustering of point defects into volds and dislocation loops leads to a microstructure in which dislocation channeling occurs. Thus the iature of the plastic zone advancing in front of a fatigue crack would be expected to change dramaticall; as shown in Fig. 13. Add1ticaally, the shearing of volds might be expected to cause branching cracks to form in front of the main fatigue cracis, Other mechanlsms proposed for factgue crack propagation would also be expected to change under 1rradiation. For example, as revtewed by Weertman, [26] Yokubari has suggested a mechanism dependent on the formation of volds ahead of the fatgue crack tip. These would be expected to form at much different rates in the



F1g. 13. presence of a highly mobile self-interstitial population whose migration will be aensitive function, of the stress state present around the crack tip.

Besides affecting the propagation rate of a fatigue crack, irradiation would also be expected to reduce the fracture toughness propert1es. Several studies have evaluated the growth of existing flaws to a coolant leak condition. Fallure by coolant leakage has generally been considered to be more critical than fracture. This is due primarily to the relatively thin. gauges of the first wall concepts evaluated so that the critical crack gize for fracture is larger than the material thickness. These analyses have generally been based on linear elast Ic fracture mechanics. This requires approprlate fracture toughness data. Because first wall gauges are relatively thin, stable flaw growth with significant plastic deformation at the crack tip might be expected to occur prior to the onset of.crack instability. However, the embrittlement which occura, due to the irradiation environments, 18 expected to make brttcle fracture, around small cracks more probable. Therefore, the linear elastic fracture mechanics analysis and associated plane strain fracture toughness propertlea are considered relevant to the first wall structures.

Fracture toughness is expected to be severely degraded by irradiation. Hawthorne and Watson [27] have studied fracture toughness trends in AISI 300 series stainless steels. They observed large decreages in postirradiation fracture toughness in 308 stainless steel welds, based on fatigue precracked Charpy $V$ specimens and J-Integral assessment procedures, For EBR-II radiation exposures at temperatures above $370^{\circ} \mathrm{C}$, fracture toughness values were reduced to as much as $20 \%$ of unirradlated values. Reductions of this magnitude will have an extremely detrimental effect on fusion reactor first wall design and 11 fe.

Since at present it is 1mpossible to predict on theoretical grounds how these different effects will combine, it is imperative that in-pile farigue data be obtained at once on candidate structural materials. Until that time, the designer has 11ttle option but to use a Universal Slopes type approach to the prediction of fatigue life.

The stress-to-rupture lifetime of a metal exposed to a fusion neutron spectrum may well be determined by the stress assisted growth of helium filled gas bubbles at the grain boundaries. The high rate of helium generation caused by the energetic fusion spectra will make this meshanism much more Important than in fission applications. Experimental verification of the potential importance of this mechanism has been demonstrated by Grossbeck, et a1. [20] who was able to show good correlatton between a calculated lifetime based ot a Huil-Rimmer [28] type calculation of 
bubble growth ratio and the experimentally

meauured rupture time.

An analysts of this mechanism showe that it is linesr in stress and reduced by a decresse in grain size as well as an increase in the fraction of helium that can be trapped in the matrices of grains. Much more attention needs to be given to this gas bubble growth mechanism which heretofore has been mainly an academic interest.

\section{B. conctusions}

The major points emerging from this review include:

1. Long lived first wall structures are Imperative for the achievement of sconomic fusion power.

2. The stress state in a tokamak first wall component is a complicated function of the module geometry, the cholce of structurel material and the irradiation conditions.

3. Stregseg can be sharply reduced by the use of selected materials, such as the ferritic steels, and the incorporation of design features such as divertors and 11ners.

4. A framework of lifetime analysis has bicen developed based on the ASLE Code Case 1592 due primartly to the work of Youngdahl and Smlth [17] and to Nelson and others [22].

5. When flaw propagation is included, - assuning the presence of undetectied flaws, much shorter lives than predicted by the ASKE based approach result.

6. Fat1gue and stress-to-rupture properties appear the most critical to the achievement of long lives by tokamak first wall modules.

7. Radiation effects on crack propagation and fracture coughness need to be much better understood through the gathering of in.reactor experimental informarton.

8. Stress-assisted bubble growth may deter. mine the stress-to-ruptuce life in a fusion environment. In reactor studies are needed under high helium generation conditions to verify the fuiportance of this mechanism.

\section{ACKNOWLEDGEMENTS}

The authors are particularly benefited from discussions with C. Youngdahl and D. L. Smith of ANL and with C. Y. LI and S. Muhkerjee of Cornell University. The typing and editing of the report by M. Eerolyn Poore $1 \mathrm{~s}$ gratefully acknowledged. 